\title{
Pituitary Gland Assessment by MR Volumetry in the Normal Indian Adolescent Population
}

\author{
Deepti Naik, Prashanth Reddy D., M. G. Srinath, A. Ashok Kumar \\ Department of Radiodiagnosis and Imaging, M.S. Ramaiah Medical College \& Hospitals, Bangalore, India
}

Email address:

drdeepti2004@hotmail.com (D. Naik),86prashanth.reddy@gmail.com (Prashnath R. D.), srinathmg@gmail.com (M. G. Srinath), drashokadekal@yahoo.com(A. A. Kumar)

\section{To cite this article:}

Deepti Naik, Prashanth Reddy D., M. G. Srinath, A. Ashok Kumar. Pituitary Gland Assessment by MR Volumetry in the Normal Indian Adolescent Population. International Journal of Medical Imaging. Vol. 3, No. 6, 2015, pp. 105-109. doi: 10.11648/j.ijmi.20150306.11

\begin{abstract}
The purpose of the study was to analyze the shapes and volumes of the pituitary gland as seen on magnetic resonance imaging using two different methods in the adolescent age group (10 to 19 years). The study was designed as a retrospective review. MRI brain was performed in 99 patients and pituitary volumes were calculated using voxel counting method and the ellipsoid formula. Pituitary shape was graded from one to five based on the surface curvature. The volume, height and shape of the pituitary in male and female patients were analyzed. The average pituitary volume by voxel counting method was found to be $0.54 \mathrm{cc} \pm 0.16 \mathrm{cc}$ in both sexes, $0.51 \pm 0.13 \mathrm{cc}$ in males and $0.56 \pm 0.19 \mathrm{cc}$ in females. The average pituitary volume by ROI was found to be $0.42 \mathrm{cc} \pm 0.16 \mathrm{cc}$ in both sexes, $0.40 \mathrm{cc} \pm 0.15 \mathrm{cc}$ in males and $0.43 \mathrm{cc} \pm 0.17 \mathrm{cc}$ in females. The average pituitary height was $0.58 \mathrm{~cm} \pm 0.15 \mathrm{~cm}$ in both sexes, $0.55 \mathrm{~cm} \pm 0.16 \mathrm{~cm}$ in males and $0.60 \mathrm{~cm} \pm 0.15 \mathrm{~cm}$ in females. The correlation coefficients between the two methods for concave shapes, for flat shapes and for convex shapes were $0.73,0.76$ and 0.60 with $\mathrm{p}$ values were $0.0007,0.0007$ and 0.0002 respectively. The average volume of the pituitary gland was $6 \%$ greater in females. There was a gradual increase in volume and height of pituitary gland with age. The two methods showed positive correlation which was statistically significant.
\end{abstract}

Keywords: Pituitary Gland Assessment, Volumetry, Adolescent

\section{Introduction}

MRI has proven to be useful in the assessment of pituitary morphology due to its excellent contrast resolution and high special resolution. T1 weighted sequences can be used to differentiate the neurohypophysis from the adenohypophysis due to the high signal intensity of the neurohypophysis ${ }^{[1]}$. Several authors have reported pituitary volumes using indirect methods and more recently by direct methods using thin section 2D and 3D MR images ${ }^{[2-5]}$. Volume measurements using 3D MR volumetry have been shown to be more accurate ${ }^{[6]}$. Most of these studies have dealt with adults. In the adolescent age group the size of the pituitary gland may be altered by both physiological and pathological processes (affected by various conditions such as growth hormone deficiency, idiopathic short stature in which the size is small and tumors, physiological hyperplasia in which the size is increased). It is important to differentiate benign causes of pituitary hyperplasia from pathological conditions ${ }^{[7]}$. To our knowledge there no publications attempting to measure the volume of the pituitary gland in normal adolescent children in the Indian population. The purpose of this study is to measure the normal volumetric growth of the pituitary gland in the adolescent age group (10 to 19 years) and to compare our findings with those of previous studies.

\section{Materials and Methods}

\subsection{Patients}

This study was designed as a retrospective review. A computerized search of the iPacs database for brain MRI examinations from February 2014 to February 2014 at M.S. Ramaiah hospitals yielded 99 patients in the age group of 10 to 19 years. Complete medical records were available for all the patients and did not reveal any factors which could alter the size of the pituitary such as endocrinopathy, tumor, pituitary surgery or certain medications.

\subsection{Image Analysis}

Scans were performed using a 1.5 T MR unit (Magnitom 
Avanto Seimens). MPRAGE $1 \mathrm{~mm}$ sections of the pituitary gland were obtained in both sagittal and coronal planes.

Image analysis procedures were performed on Osirix

Maximal pituitary height was determined from midline sagittal images by measuring the greatest distance between the superior and inferior borders of the gland. Criteria for midline image were visualization of the pituitary stalk, sylvian aqueduct and high signal intensity of the neurohypophysis. Lateral and anteroposterior dimensions were similarly determined by measuring the greatest dimensions on coronal and sagittal images, respectively. The volume of interest was determined by manual tracing with a mouse guided pointer.

Volume was estimated in two ways:

1) Using the simplified ellipsoid formula length $x$ height $x$ width / 2

2) Voxel counting method within a region of interest.

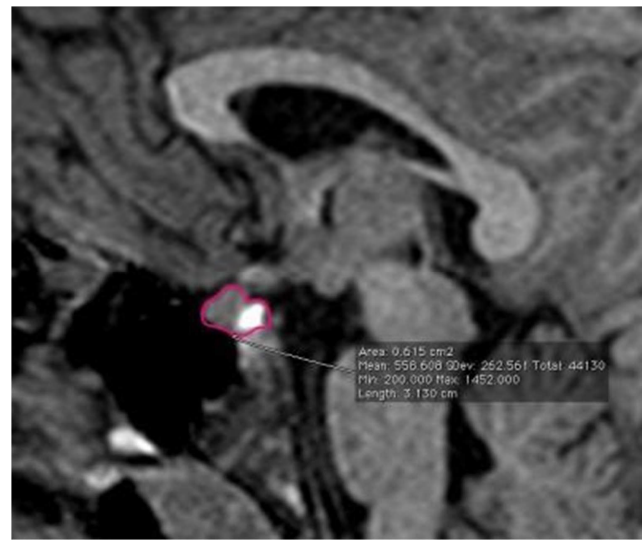

Figure 1. Pituitary volume assessment by ROI.
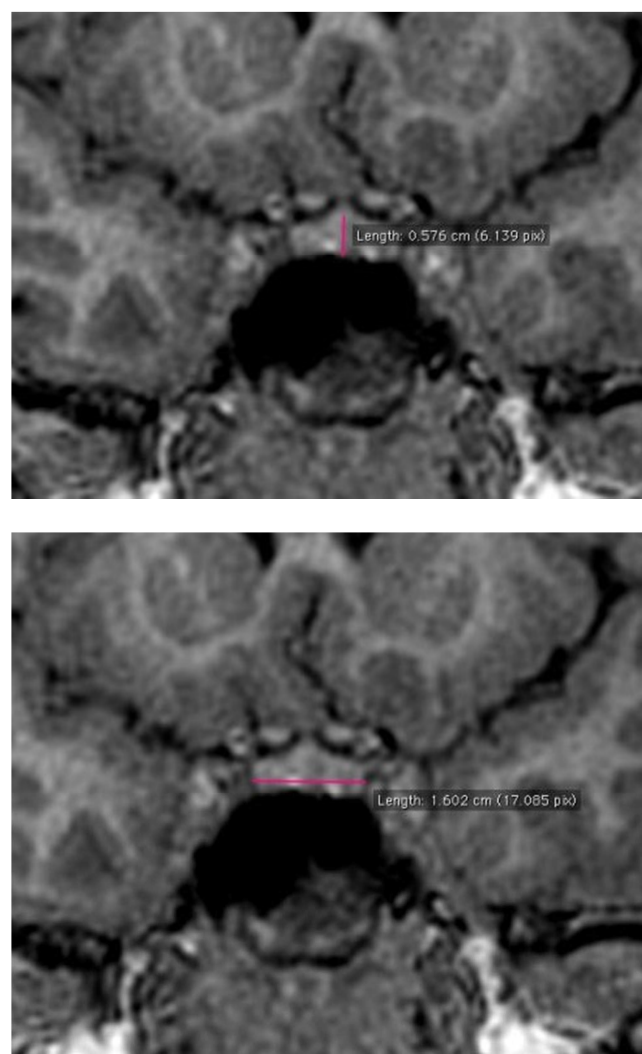

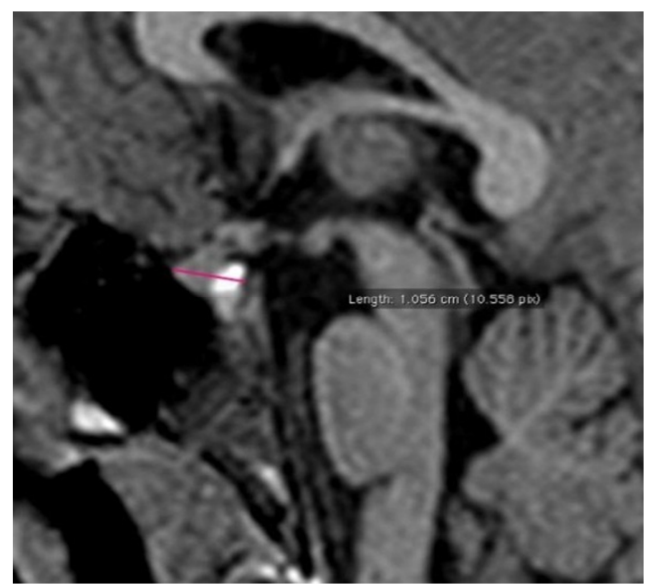

Figure 2. Measurement of Pituitary Length, Height and Width.

The shape of the pituitary gland was graded from 1 to 5 based on the contour of the superior surface of the pituitary gland on sagittal and coronal views.
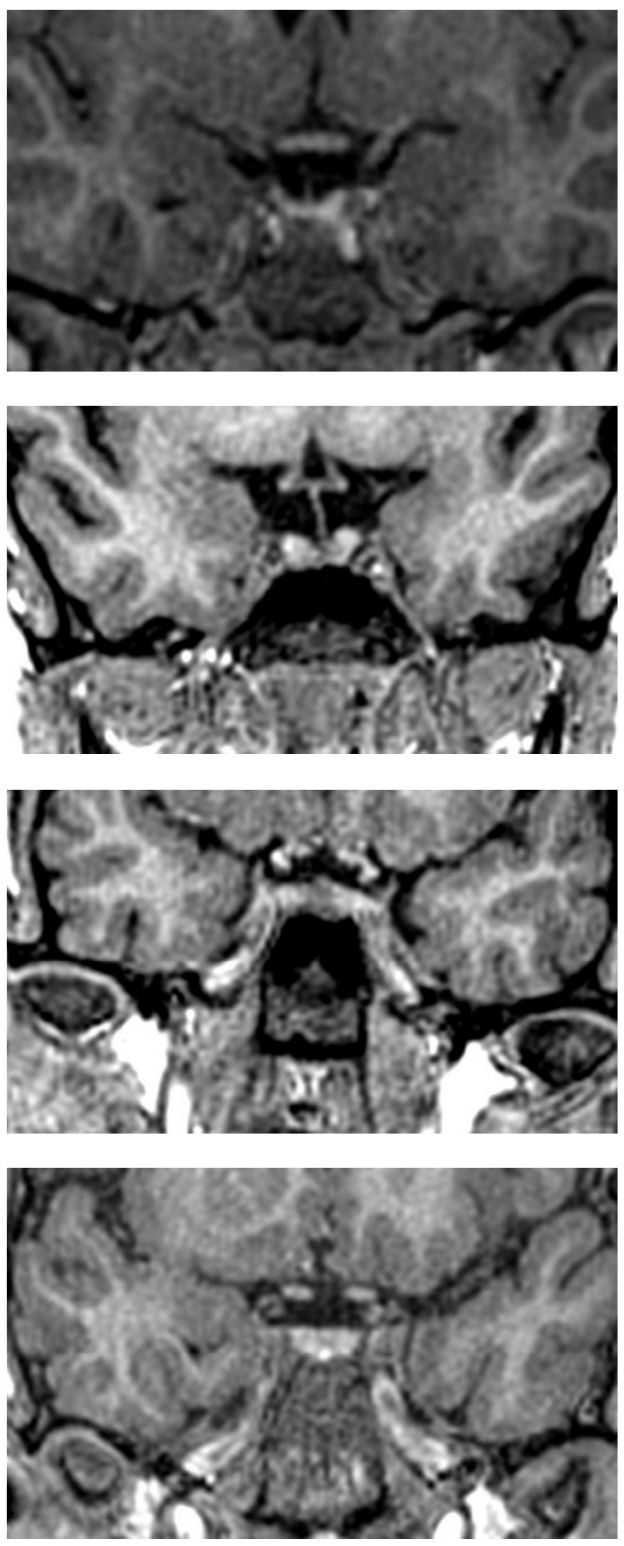


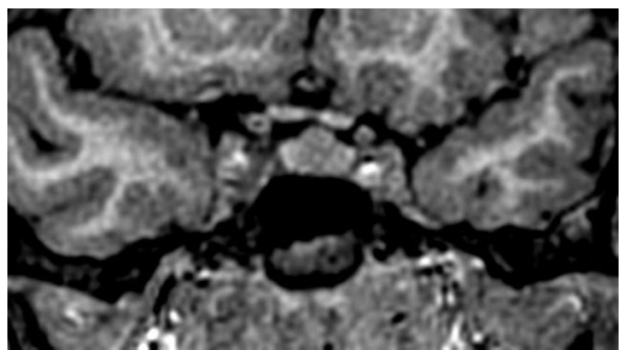

Figure 3. Grades of pituitary shapes in coronal plane-Grade I to Grade V.
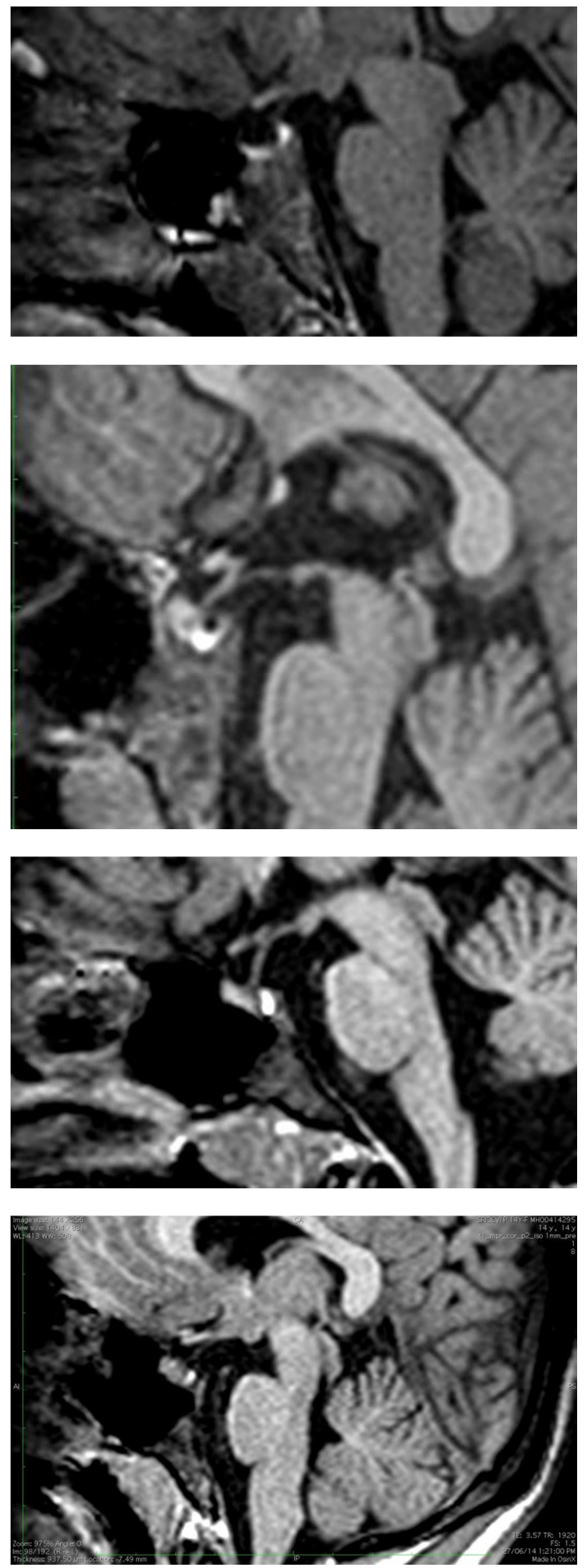

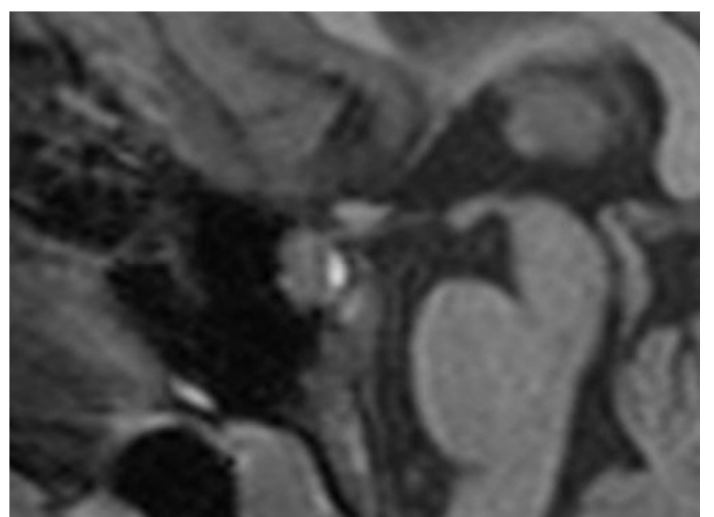

Figure 4. Grades of pituitary shapes in sagittal plane-Grade I to Grade V.

\subsection{Statistical Analysis}

Data analysis was done using SPSS. Patients were stratified according to age and sex. Mean and standard deviation were calculated for all the data and expressed using tables and graphs. Pearson's correlation was used to assess the relationships between age, sex and pituitary dimensions. $\mathrm{P}$ value of $<0.05$ was considered significant.

\section{Results}

Out of the 99 subjects (44 male, 55 female) the mean pituitary volume using the ellipsoid formula was $0.43 \pm$ $0.17 \mathrm{cc}$ in females and $0.39 \pm 0.15 \mathrm{cc}$ in males and using the voxel counting method was $0.56 \pm 0.19 \mathrm{cc}$ in females and $0.51 \pm 0.13 \mathrm{cc}$ in males. The mean pituitary height, length and width for males and female were $1.01 \pm 0.13 \mathrm{~cm}, 0.55 \pm 0.16$ $\mathrm{cm}, 1.4 \pm 0.15 \mathrm{~cm}$ and $1.01 \pm 0.14 \mathrm{~cm}, 0.59 \pm 0.15 \mathrm{~cm}$ and 1.4 $\pm 0.24 \mathrm{~cm}$ respectively. Of all the measurements height showed the best correlation with pituitary volume.

The two methods showed strong positive correlation $(\mathrm{r}=$ $0.715)$ with $p$ value $<0.01$

There was a moderate correlation between all pituitary measurements $(r=0.4)$ and age with $p$ value $<0.01$. There was a gradual increase in pituitary height with age. No growth spurt was observed.

Females had a slightly larger pituitary gland but the difference was not statistically significant.

Flat pituitary was the most common type of pituitary shape. Convex pituitary shape was more common in females. Convex glands also had larger volumes.

There was no relationship between the volume of the neurohypophysis and either age or sex.

Table 1. Mean and standard deviation of pituitary gland dimensions and volumes in females.

\begin{tabular}{lll}
\hline Females (N=55) & & \\
\hline & Mean & SD \\
\hline Length & $1.016 \mathrm{~cm}$ & $0.1421 \mathrm{~cm}$ \\
Height & $0.5970 \mathrm{~cm}$ & $0.1486 \mathrm{~cm}$ \\
Width & $1.407 \mathrm{~cm}$ & $0.2477 \mathrm{~cm}$ \\
Pituitary volume by ellipsoid formula & $0.427 \mathrm{cc}$ & $0.1739 \mathrm{cc}$ \\
Pituitary Volume by ROI & $0.559 \mathrm{cc}$ & $0.1905 \mathrm{cc}$ \\
\hline
\end{tabular}


Table 2. Mean and standard deviation of pituitary gland dimensions and volumes in Males.

\begin{tabular}{lll}
\hline Males (N=44) & & \\
\hline Mength & Sean & SD \\
Height & $1.019 \mathrm{~cm}$ & $0.1311 \mathrm{~cm}$ \\
Width & $0.551 \mathrm{~cm}$ & $0.1560 \mathrm{~cm}$ \\
Pituitary volume by ellipsoid formula & $1.395 \mathrm{~cm}$ & $0.1496 \mathrm{~cm}$ \\
Pituitary Volume by ROI & $0.392 \mathrm{cc}$ & $0.1490 \mathrm{cc}$ \\
\hline
\end{tabular}

\section{Discussion}

Despite its small size the pituitary gland plays a major role in neuroendocrine regulation. In this study we found the mean pituitary height to be $0.58 \mathrm{~cm}$ and volume to be $0.54 \mathrm{cc}$ which is comparable to other studies ${ }^{[8-11]}$. Measurements in these studies rely on linear parameters and since the pituitary gland develops dynamically in puberty a more accurate method of measurement may be required to differentiate the normal from the abnormal pituitary gland. Hence, we used a voxel counting method which directly measures the pituitary volume. There are only a few studies reporting normative, directly measured, volumetric data on pituitary size.

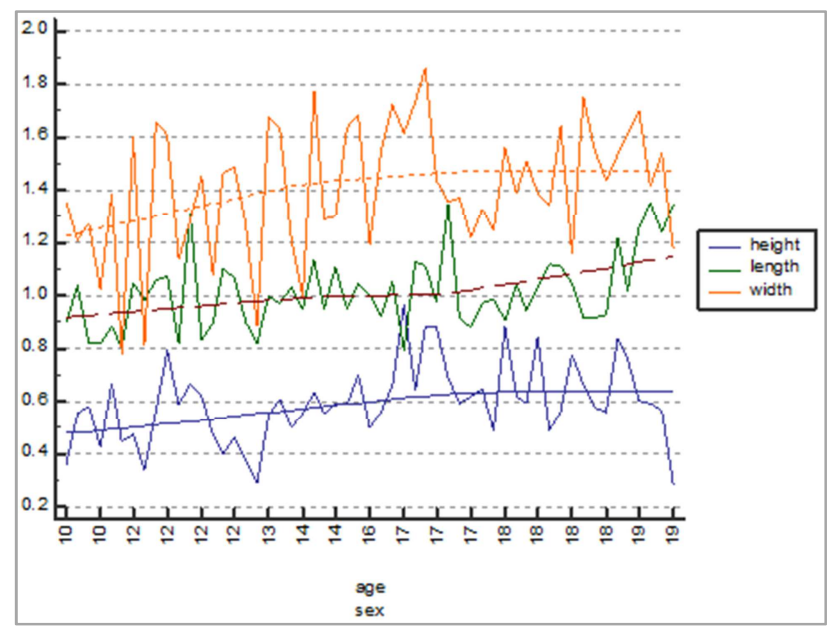

Figure 5. Graph showing increase in pituitary gland dimensions with age.

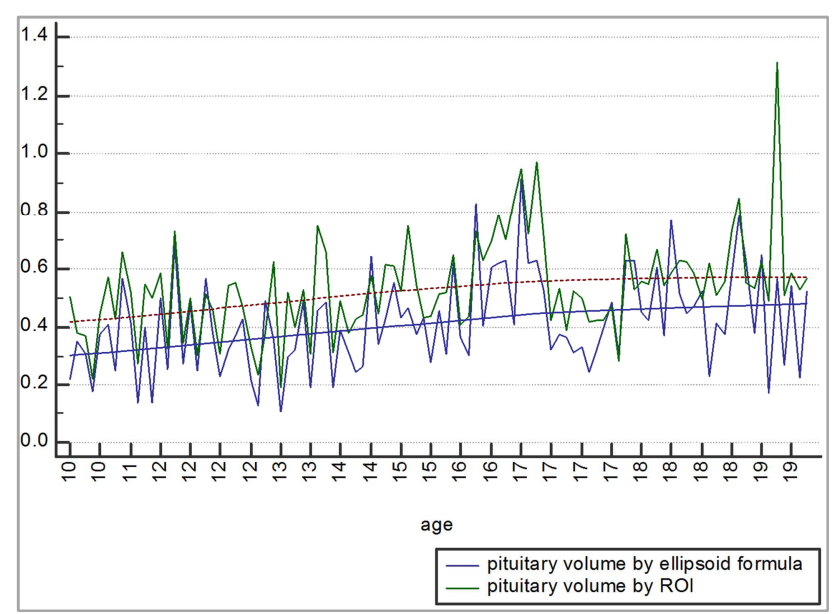

Figure 6. Pituitary gland volumes measured by ellipsoid formula and by voxel counting method.
The only other published data on whole pituitary gland volume in a similar age group as in our study are by Takano et $\mathrm{al}^{[12]}$. In their study on 199 Japanese children aged 0 to 19 years a growth spurt was observed which was more prominent in girls, unlike that seen in our study. They also reported gradual growth of the posterior pituitary without a spurt however, in our study there was no growth of the posterior pituitary observed. This study reported average pituitary volumes in males and female in the age group of 10 to 19 years of $0.51 \mathrm{cc}$ and $0.61 \mathrm{cc}$ respectively which correspond to the results of our study.

It has been well documented that the size of the pituitary varies with age. Some authors have also reported sex differences in pituitary volumes with females having slightly larger glands ${ }^{[13,14]}$. Our study did not show a statistically significant difference in pituitary volume between the two sexes. Changes in the shape of the upper surface of the pituitary gland occur with age and are more pronounced in females varying from concave to flat and a convex bulging appearance ${ }^{[15,16]}$. The results of these studies are similar to our own.

There is a vast variation in the shape of the normal pituitary gland. In distinction to a study performed on prepubertal children in Australia our study showed a significant positive correlation between linear dimensions and volume which was greatest for pituitary height ${ }^{[6]}$.
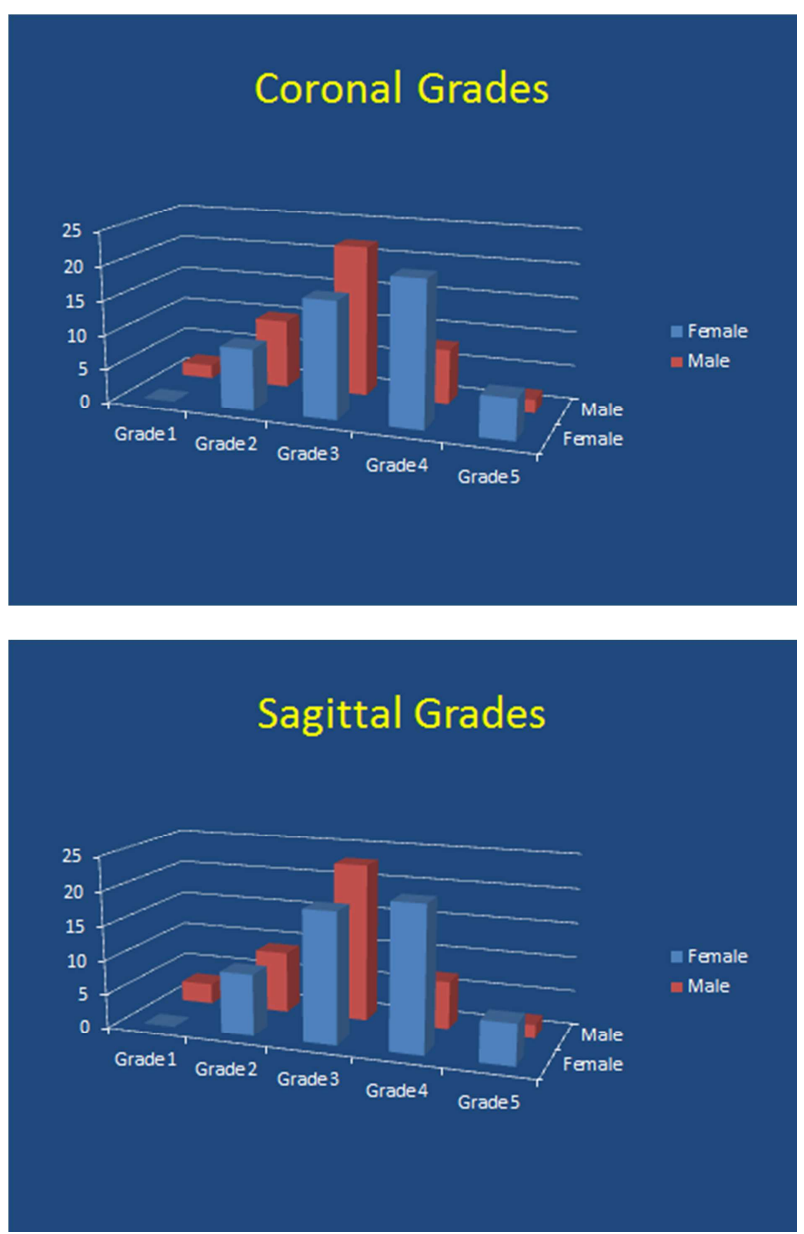

Figure 7 \& 8. Grades of pituitary shape on coronal and sagittal images. 
Table 3. Alteration of pituitary gland volume with shape.

\begin{tabular}{|c|c|c|c|c|c|c|c|c|c|c|}
\hline \multicolumn{11}{|l|}{ Shape Grade in Sagittal } \\
\hline & 1 & & 2 & & 3 & & 4 & & 5 & \\
\hline & Mean & SD & Mean & SD & Mean & SD & Mean & SD & Mean & SD \\
\hline Pituitary Volume by Ellipsoid formula & 0.1880 & 0.0575 & 0.3470 & 0.1491 & 0.3820 & 0.1125 & 0.4660 & 0.1637 & 0.6720 & 0.1270 \\
\hline \multirow{3}{*}{$\begin{array}{l}\text { Pituitary Volume by Region of Interest } \\
\text { Shape Grade in Coronal }\end{array}$} & 0.3250 & 0.0976 & 0.5350 & 0.1554 & 0.4880 & 0.1395 & 0.5580 & 0.1141 & 0.8050 & 0.2335 \\
\hline & 1 & & 2 & & 3 & & 4 & & 5 & \\
\hline & Mean & SD & Mean & SD & Mean & SD & Mean & SD & Mean & SD \\
\hline Pituitary Volume by Ellipsoid formula & 0.1860 & 0.0811 & 0.2880 & 0.1172 & 0.4190 & 0.1095 & 0.4370 & 0.1694 & 0.6420 & 0.1357 \\
\hline Pituitary Volume by Region of Interest & 0.3320 & 0.1370 & 0.4690 & 0.1592 & 0.5240 & 0.1379 & 0.5310 & 0.1245 & 0.7700 & 0.2202 \\
\hline
\end{tabular}

\section{Limitations}

Our study may be limited by selection bias as the high cost of MRI examination prohibited inclusion of normal volunteers in the study. Patients without imaging or clinical evidence of neuroendocrine pathology were selected.

\section{Conclusions}

We has assessed two methods for measuring pituitary volume and provided reference values for normal pituitary dimensions and volume in an Indian population in the age group of 10 to 19 years. Both linear and volumetric measurement of pituitary volume showed a strong positive correlation. There was an increase in pituitary volume with age. There was no significant sex related difference in pituitary volume.

\section{References}

[1] Kucharczyk J, Kucharczyk W, Berry I, et al. Histochemical characterization and functional significance of the hyperintense signal on MR images of the posterior pituitary. AJR Am J Roentgenol 1989; 152:153-157 ES.

[2] Lurie SN, Doraiswamy PM, Husain MM, et al. In vivo assessment of pituitary gland volume with magnetic resonance imaging: the effect of age. J Clin Endocrinol Metab 1990; 71:505-508.

[3] Gonzalez JG, Elizondo G, Saldivar D, Nanez H, Todd L, Villarreal JZ. Pituitary gland growth during normal pregnancy: an in vivo study using magnetic resonance imaging. Am J Med $1988 ; 85: 217-220$.

[4] Krishnan KRR, Doraiswamy PM, Lurie SN, et al. Pituitary size in depression. J Clin Endocrinol Metab 1991; 72:256-259.

[5] Sharafuddin MJA, Luisiri A, Garibaldi LR, et al. MR imaging diagnosis of central precocious puberty: importance of changes in the shape and size of the pituitary gland. AJR Am J Roentgenol 1994; 162:1167-1173.
[6] Fink AM, Vidmar S, Kumbla S, et al. Age-related pituitary volumes in prepubertal children with normal endocrine function: volumetric magnetic resonance data. J Clin Endocrinol Metab. 2005 Jun; 90(6):3274-8.

[7] Miyuki Takasu, Chihiro Tani, Yoko Kaichi et al.Pituitary Volumes and Functions in Children with Growth Hormon Deficiency: Volumetric Magnetic Resonance Findings. Journal of Endocrinology and Diabetes Mellitus, 2014, 2, 39-44.

[8] Ibinaiye PO, Olarinoye-Akorede S, Kajogbola O, Bakari AG. Magnetic Resonance Imaging Determination of Normal Pituitary Gland Dimensions in Zaria, Northwest Nigerian Population. Journal of Clinical Imaging Science. 2015; 5:29.

[9] Koichi T, Hidetsuna U, Hiroyuki O et al.Normal Development of the Pituitary Gland: Assessment with Three-dimensional MR Volumetry. AJNR 1999 20: 312-315.

[10] Ikram MF, Sajjad Z, Shokh IS, Omair A. Pituitary height on magnetic resonance imaging observation of age and sex related changes. J Pak Med Assoc. 2008; 58:261-5.

[11] Denk CC, Onderoğlu S, Ilgi S, Gürcan F. Height of normal pituitary gland on MRI: Differences between age groups and sexes. Okajimas Folia Anat Jpn. 1999; 76:81.

[12] Takano K, Utsunomiya H, Ono H, Ohfu M, Okazaki M 1999 Normal development of the pituitary gland: assessment with three-dimensional MR volumetry. AJNR Am J Neuroradiol 20:312-315.

[13] Suzuki M, Takashima T, Kadoya M, Konishi H, Kameyama T, Yoshikawa J, et al. Height of normal pituitary gland on MR imaging: Age and sex differentiation. J Comput Assist Tomogr. 1990; 14:36-9.

[14] Argyropoulou M, Perignon F, Brunelle F, Brauner R, Rappaport R. Height of normal pituitary gland as a function of age evaluated by magnetic resonance imaging in children. Pediatr Radiol. 1991; 21:247-9.

[15] Kato K, Saeki N, Yamaura A. Morphological changes on MR imaging of the normal pituitary gland related to age and sex: Main emphasis on pubescent females. J Clin Neurosci. 2002; 9:53-6.

[16] Doraiswamy PM, Potts JM, Axelson DA, et al. MR assessment of pituitary gland morphology in healthy volunteers: Age- and gender-related differences. AJNR Am J Neurodiol. 1992; 13:1295-9. 